\title{
Influence of Respiratory Dead Space on Lung Clearance Index in Preterm Infants
}

\author{
Roland P. Neumann, MD, ${ }^{a *}$, J. Jane Pillow, FRACP, PhD, ${ }^{b, c}$ Cindy Thamrin, PhD, ${ }^{d}$ \\ Urs Frey, MD, PhD ${ }^{e}$, Sven M. Schulzke, FRACP, $M \mathrm{MS}^{\mathrm{a}, \mathrm{b}}$
}

${ }^{a}$ Department of Neonatology, University of Basel Children's Hospital, Basel, Switzerland

${ }^{b}$ Centre of Neonatal Research and Education, School of Pediatrics and Child Health, University of Western Australia, Perth, Australia

'School of Anatomy, Physiology and Human Biology, University of Western Australia, Perth,

Australia

${ }^{d}$ Woolcock Institute of Medical Research, Glebe, Australia

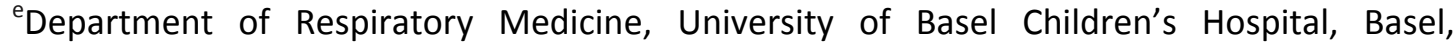
Switzerland

*Correspondending author at: University of Basel Children's Hospital (UKBB), Department of Neonatology, Spitalstrasse 33, 4031 Basel, Switzerland. Phone 0041-612659564, Fax 0041612659568. Email address: roland.neumann@ukbb.ch 


\section{Abstract}

Lung clearance index $(\mathrm{LCl})$, a marker of ventilation inhomogeneity derived from multiple breath washout (MBW), is used for clinical monitoring and as a key outcome of clinical trials in infants and children with cystic fibrosis. Utility of $\mathrm{LCl}$ is controversial in preterm infants with bronchopulmonary dysplasia (BPD) who tend to have high dead space to tidal volume ratio $\left(V_{\mathrm{D}} / V_{\mathrm{T}}\right)$. We investigated the effect of $V_{\mathrm{D}} / V_{\mathrm{T}}$ on $\mathrm{LCl}$ in a cohort of preterm infants with and without BPD and term healthy controls. We analysed MBW data from 455 infants at a mean (SD) of 43.4 (3.5) w postmenstrual age. $V_{\mathrm{D}}$ was estimated from the molar mass signal of an ultrasonic flowmeter $\left(V_{D, M M}\right)$. LCl was associated with $V_{D, M M} / V_{T}\left(r^{2}=0.13, p<0.001\right)$ but was not associated with BPD. Adjusting for $V_{\mathrm{D}, \mathrm{MM}} / V_{\mathrm{T}}$ did not reveal an association between $\mathrm{LCl}$ and BPD. We conclude that $V_{\mathrm{D}, \mathrm{MM}} / V_{\mathrm{T}}$ is a relevant factor when interpreting $\mathrm{LCl}$ in this population but the effect size of this association is moderate. 


\section{Introduction}

Bronchopulmonary dysplasia (BPD) remains a major complication of very preterm birth. BPD in preterm infants is pragmatically defined as a requirement of supplemental oxygen for at least 28 days from birth and its severity is commonly diagnosed at 36 weeks (w) postmenstrual age (PMA) (1). The incidence of BPD is inversely related to gestational age (GA) at birth and at least $40 \%$ of preterm infants born before 29 w GA are diagnosed with BPD (2). Current phenotypes of BPD are characterized by abnormal lung development resulting in impaired alveolar, airway and vascular growth. Histopathological features of BPD include reduced alveolar count, enlarged alveoli, decreased airway calibre, peribronchial fibrosis, and a dysmorphic microvascular network (3). BPD is associated with increased mortality and respiratory morbidity, poor neurodevelopmental outcome and reduced exercise capacity (4).

BPD commonly results in airflow limitation starting from early infancy and continuing into childhood and late adolescence $(5,6)$. Conventional spirometric lung function tests are not suited to assess peripheral regions of the lung where histological abnormalities of BPD are primarily located (7). Multiple breath inert-gas washout technique (MBW) is advantageous for assessment of the lung periphery as it quantifies lung volume and ventilation inhomogeneity. Lung clearance index $(\mathrm{LCl})$ is a MBW outcome measure that quantifies ventilation inhomogeneity (8). $\mathrm{LCl}$ is a sensitive marker of abnormal lung function in children with cystic fibrosis and is a central outcome measure in cystic fibrosis therapy trials (9-12). Hjalmarson and Sandberg found increased $\mathrm{LCl}$ in preterm compared to term infants; importantly, they further demonstrated a strong association between $\mathrm{LCl}$ and the severity of BPD in preterm infants measured at term corrected age using nitrogen washout technique $(13,14)$. In contrast, several recent studies failed to confirm those associations (15-17). Besides differences in overall equipment setup and methodology, these conflicting results could potentially be explained by confounding factors such as the respiratory dead space to 
tidal volume ratio $\left(V_{\mathrm{D}} / V_{\mathrm{T}}\right)$ which might influence the association between $\mathrm{LCl}$ and $\mathrm{BPD}$ : $\mathrm{LCl}$ is calculated as the number of lung turnovers (cumulative expired volume at the point where end-tidal inert gas concentration falls below $1 / 40$ th of the original concentration), divided by the functional residual capacity (FRC). Thus, increased $V_{\mathrm{D}} / V_{\mathrm{T}}$ directly contributes to cumulative expired volume (CEV) and consequently, might elevate $\mathrm{LCl}$ as suggested in simulation studies (18). Infants, and particularly those with BPD, have increased $V_{D} / V_{T}$ compared to older children and adults. Therefore, the influence of $V_{\mathrm{D}} / V_{\mathrm{T}}$ on the association between $\mathrm{LCl}$ and lung disease might be highly relevant in this population.

We aimed to explore the influence of the respiratory dead space (estimated from the molar mass signal) to tidal volume ratio $\left(V_{\mathrm{D}, \mathrm{MM}} / V_{\mathrm{T}}\right)$ on $\mathrm{LCl}$ in preterm and term infants using $\mathrm{MBW}$ data from two previously reported cohort studies of infant lung function $(16,17)$. We hypothesized that a) $V_{\mathrm{D}, \mathrm{MM}} / V_{\mathrm{T}}$ is associated with $\left.\mathrm{LCl}, \mathrm{b}\right) \mathrm{LCl}$ is associated with $\mathrm{BPD}$ and other indicators of neonatal lung disease (duration of oxygen supplementation, duration of mechanical ventilation) after adjusting for $V_{\mathrm{D}, \mathrm{MM}} / V_{\mathrm{T}}$, and $\mathrm{c}$ ) preemptively calculating $\mathrm{LCl}$ on an alveolar level (aLCl), i.e., using a modified $\mathrm{LCl}$ correcting CEV for $V_{\mathrm{D}, \mathrm{MM}}$, is superior to conventional $\mathrm{LCl}$ in discriminating between infants with and without BPD. 


\section{Materials and Methods}

\subsection{Study design}

We performed a retrospective analysis of infant lung function data from two prospective cohort studies conducted in Berne, Switzerland and Perth, Australia. Primary objectives of these cohort studies were to assess the impact of prematurity and neonatal lung disease on infant lung function. The main results of those studies are published elsewhere $(16,17)$.

\subsection{Ethics statement}

Studies were approved by the local research ethics committees (The Bernese Cantonal Ethics Committee, Bern, Switzerland and Women \& Newborn Health Service Research Ethics Committee, Perth, Australia) and written informed parental consent was obtained prior to lung function testing.

\subsection{Study subjects}

Detailed recruitment strategies are described elsewhere $(16,17)$. Briefly, term and preterm infants were recruited from the maternity and neonatal units at The University Children's Hospital of Berne, Switzerland and at King Edward Memorial Hospital for Women, Perth, Australia. Detailed antenatal and neonatal history was recorded. BPD was defined as supplemental oxygen requirement for at least 28 days (1). Severity of BPD was classified at 36 w PMA for infants born below 32 w GA and at day 56 or at discharge home for infants born after 32 w GA, whichever came first, depending on their oxygen requirement: infants breathing room air were diagnosed with mild BPD; infants requiring supplemental oxygen or positive pressure support were diagnosed with moderate to severe BPD.

\subsection{Lung function tests}

Details of lung function tests were described previously $(16,17)$. In brief, we studied infants during quiet, unsedated sleep in supine position following a regular feed. Tidal breathing parameters including respiratory rate $(\mathrm{RR})$ and tidal volume $\left(V_{T}\right)$ were recorded after placement of a face mask (Size 1; Homedica AG, Hünenberg, $\mathrm{CH}$ ) using an ultrasonic flow 
meter (Spiroson; Ecomedics AG, Duernten, Switzerland) and in accordance with current European Respiratory Society/American Thoracic Society standards for infant lung function testing $(19,20)$. FRC and $\mathrm{LCl}$ were determined by MBW technique with $4 \%$ sulfur hexafluoride $\left(\mathrm{SF}_{6}\right)$ as a tracer gas. Flow (range $\pm 0.5 \mathrm{~L} / \mathrm{s}$, resolution $0.6 \mathrm{~mL} / \mathrm{s}$ ) and molar mass (MM) (range $20-45 \mathrm{~g} / \mathrm{mol}$, resolution $0.01 \mathrm{~g} / \mathrm{mol}$ ) were sampled at $200 \mathrm{~Hz}$ and corrected for body temperature and ambient pressure, and saturated with water vapor conditions. LCI was calculated based on the end-expiratory MM signal of the MBW trace as recommended by the manufacturer. However, recent literature suggests that $\mathrm{LCl}$ derived from the endexpiratory molar mass (EEMM) signal compared to the end-inspiratory molar mass (EIMM) signal might result in falsely normal $\mathrm{LCl}$ in infants with cystic fibrosis (21). Thus, we additionally calculated $\mathrm{LCl}$ using the EIMM signal. The instrumental dead space $\left(V_{\mathrm{D}, \text { app }}\right)$ of the ultrasonic flow sensor and that of the face mask were 1.9 and $7.5 \mathrm{~mL}$, respectively. We calculated respiratory dead space $\left(V_{\mathrm{D}, \mathrm{MM}}\right)$ from the $\mathrm{MM}$ signal of the ultrasonic flow meter as reported previously (22). Briefly, $V_{D, M M}$ was estimated as the volume of air that passes through the ultrasonic flow meter until the $\mathrm{MM}$ signal augments to its $10 \%$ rise point. $V_{\mathrm{D}, \mathrm{MM}}$ was calculated breath-by-breath from at least 10 breaths available within each measurement prior to $\mathrm{MBW}$, and averaged to obtain the mean $V_{\mathrm{D}, \mathrm{MM}}$ for the whole measurement. $V_{\mathrm{D}, \mathrm{MM}}$ estimation from a breath was excluded if the $\mathrm{MM}$ profile was markedly different from those of other breaths within the measurement or if there was uncertainty about the $10 \% \mathrm{MM}$ rise point due to noise or multiple rise points. $V_{\mathrm{D}, \mathrm{MM}}$ is a composite of biological dead space and $V_{\mathrm{D}, \mathrm{app}}$ and acceptable agreement between $V_{\mathrm{D}, \mathrm{MM}}$ and Fowler $V_{\mathrm{D}}$ derived from a $\mathrm{CO}_{2}$ analyser has been shown although $V_{\mathrm{D}, \mathrm{MM}}$ might slightly underestimate $V_{\mathrm{D}}$ compared to the Fowler method (22). Alveolar tidal volume $\left(V_{\text {alv }}\right)$ was calculated as $\left(V_{T}-\right.$ $\left.V_{\mathrm{D}, \mathrm{MM}}\right) . \mathrm{LCl}$ was calculated as the cumulative expired volume at the point where end-tidal inert gas concentration falls below $1 / 40$ th of the original concentration, divided by FRC. aLCI was calculated similarly, but after correcting for $V_{\mathrm{D}, \mathrm{MM}}$ as follows: 
$\mathrm{aLCl}=\left(\right.$ cumulative expired volume $-\left(\right.$ number of breaths $\left.\left.* V_{\mathrm{D}, \mathrm{MM}}\right)\right) /\left(\mathrm{FRC}-V_{\mathrm{D}, \mathrm{MM}}\right)$. 


\subsection{Statistical analyses}

Differences in lung function of term healthy and preterm infants with and without BPD were explored using one-way ANOVA with Scheffe post-hoc test for group comparisons. We investigated the influence of explanatory variables on $\mathrm{LCl}$ and aLCl using multivariable linear regression analysis. We considered the following explanatory variables: GA at birth, birth weight z-score (calculated from the British Growth Reference (23)), PMA at test, body size and body composition at test (weight, weight z-score (23) and body length), total days of oxygen supplementation assessed at test, days of mechanical ventilation in the neonatal intensive care unit, presence of mild and moderate to severe $\mathrm{BPD}, V_{\mathrm{D}, \mathrm{MM}} / V_{\mathrm{T}}$, minute ventilation, centre, sex, and passive smoke exposure. Factors known to influence outcomes (e.g., centre) and those potentially influencing the outcome variable in univariable regression analysis $(p<0.15)$ were explored further by multivariable linear regression analysis using a stepwise backward elimination strategy, in which a $p$ value $<0.05$ was considered statistically significant. All statistical analyses were performed using Stata 11 software (StataCorp. 2009. Stata Statistical Software: Release 11. College Station, TX: StataCorp LP.). 


\section{Results}

\subsection{Baseline characteristics of study participants}

We analysed measurements from a total of 455 infants (222 term, 233 preterm). Lung function tests were performed at a mean (SD) of $43.4( \pm 3.5)$ w PMA. Demographic and clinical characteristics of included infants are given in Table 1.

\subsection{Results of lung function tests}

Table 2 summarises the results of lung function tests for healthy term and preterm infants and for infants with mild and moderate to severe BPD. There were no significant differences in $\mathrm{LCl}$ between groups. aLCI was significantly lower in infants with moderate to severe BPD compared to healthy preterm infants but not to healthy term infants or preterm infants with mild BPD. Calculating FRC, LCI, and aLCI from the EIMM signal resulted in lower FRC values and higher values for $\mathrm{LCl}$ and $\mathrm{aLCl}$ but there were no significant differences in those outcomes between groups (Supplemental Table 1, Supplemental Fig. 1). Within-subject within-test repeatability (coefficient of variation, CV) of $\mathrm{FRC}, \mathrm{LCl}, V_{\mathrm{T}}$ and $V_{\mathrm{D}, \mathrm{MM}}$ were $5.8 \%$, $7.0 \%, 5.8 \%$, and $8.7 \%$, respectively.

\subsection{Association of clinical characteristics and lung function parameters with $\mathrm{LCl}$}

In univariable analyses, $\mathrm{LCl}$ was positively associated with days of supplemental oxygen, $V_{\mathrm{D}, \mathrm{MM}} / V_{\mathrm{T}}, \mathrm{PMA}>40 \mathrm{w}$ and $\mathrm{MV} / \mathrm{kg}$ (Table 3, Fig. 1). There was no association of LCl with GA, $\mathrm{BPD}$, and duration of mechanical ventilation. In multivariable analysis, $V_{\mathrm{D}, \mathrm{MM}} / V_{\mathrm{T}}$, centre and PMA > $40 \mathrm{w}$ but not neonatal lung disease including BPD, duration of supplemental oxygen, and duration of mechanical ventilation were significantly associated with $\mathrm{LCl}$ and explained $19 \%$ of the variability in $\mathrm{LCl}\left(r^{2}=0.19, p<0.001\right)$ (Table 4). Supplemental Table 2 summarises results of univariable analyses of $\mathrm{LCl}$ calculated using the EIMM signal. Multivariable analysis of $\mathrm{LCl}$ calculated using the EIMM signal revealed an association with $V_{\mathrm{D}, \mathrm{MM}} / V_{\mathrm{T}}$, centre and weight at test but not with neonatal lung disease including BPD, 
duration of supplemental oxygen, and duration of mechanical ventilation $\left(r^{2}=0.12, p<\right.$ 0.001) (Supplemental Table 4).

\subsection{Association of clinical characteristics and lung function parameters with aLCI}

Table 5 summarizes findings of univariable analyses. In multivariable regression analysis, $V_{\mathrm{D}, \mathrm{MM}} / V_{\mathrm{T}}$, centre, post-menstrual age $>40 \mathrm{w}$, and length, but not neonatal lung disease including BPD, duration of supplemental oxygen, and duration of mechanical ventilation were significantly associated with aLCl and explained $47 \%$ of the variability in aLCl $\left(r^{2}=0.47\right.$, $p=<0.001$ ) (Table 6). Supplemental Table 3 summarises results of univariable analyses of aLCl calculated using the EIMM signal. Multivariable analysis of aLCl calculated using the EIMM signal revealed an association with $V_{\mathrm{D}, \mathrm{MM}} / V_{\mathrm{T}}$, centre, length at test, and sex but not with neonatal lung disease including BPD, duration of supplemental oxygen, and duration of mechanical ventilation $\left(r^{2}=0.20, p<0.001\right)($ Supplemental Table 5). However, aLCl calculated by either method was negatively associated with $V_{\mathrm{D}, \mathrm{MM}} / V_{\mathrm{T}}$ in these models. 


\section{Discussion}

We found a positive association of $\mathrm{LCl}$ with $V_{\mathrm{D}, \mathrm{MM}} / V_{\mathrm{T}}$ but not with BPD. Adjusting for $V_{\mathrm{D}, \mathrm{MM}} / V_{\mathrm{T}}$ did not reveal an association of $L C l$ with BPD. Similarly, preemptively calculating aLCl did not show an association of $\mathrm{aLCl}$ with BPD or other indicators of neonatal lung disease and resulted in biologically questionable negative associations of aLCl with $V_{\mathrm{D}, \mathrm{MM}} / V_{\mathrm{T}}$. These results suggest that $V_{\mathrm{D}, \mathrm{MM}} / V_{\mathrm{T}}$ does impact on $\mathrm{LCl}$ calculations in term and preterm infants with and without BPD. Further, $\mathrm{LCl}$ and $\mathrm{aLCl}$ as indicators of ventilation inhomogeneity derived from $\mathrm{MBW}$ with $\mathrm{SF}_{6}$ have very limited diagnostic utility in this specific population.

To the best of our knowledge, this is the first study systematically assessing the influence of $V_{\mathrm{D}, \mathrm{MM}} / V_{\mathrm{T}}$ on $\mathrm{LCl}$ in term and preterm infants with and without BPD in quiet, unsedated sleep. Schmalisch et al. studied the effect of changing ventilator settings on $\mathrm{LCl}$ and several other indices of ventilation inhomogeneity in computer and animal models of small ventilated lungs (24). They found that $\mathrm{LCl}$ increased with $V_{\mathrm{D}} / V_{\mathrm{T}}$ and, to a smaller extend, with $V_{\mathrm{T}} / \mathrm{FRC}$ (24). They concluded that $V_{D} / V_{T}$ should be appreciated when assessing indices of ventilation inhomogeneity in small ventilated lungs. Recently, Schmalisch et al. showed a positive association of $V_{\mathrm{D}} / V_{\mathrm{T}}$ with $\mathrm{LCl}$ in a retrospective cohort study in preterm infants (25). However, those infants were sedated with chloral hydrate, potentially altering their breathing pattern and lung function outcomes $(26,27)$. Further, our method of $V_{D}$ calculation using $V_{D, M M}$ - which shows acceptable agreement with Fowler $V_{D}(22)$ - is different from that used in the latter study and results in slightly higher values for $V_{D}(1.9 \mathrm{~mL} / \mathrm{kg} \mathrm{vs}$. $1.1 \mathrm{~mL} / \mathrm{kg}$ body weight) $(22,25) . V_{D, M M}$ compared to Fowler $V_{D}$ might underestimate $V_{D}$ in infants with BPD, however, it is not clear which method better reflects the "true" respiratory $V_{D}$ in infants (22). Despite those methodological differences, the results of our study are similar to those reported by Schmalisch et al., indicating that the association between $V_{\mathrm{D}} / V_{\mathrm{T}}$ and $\mathrm{LCl}$ is remarkably robust in preterm infants. 
$\mathrm{LCl}$ is a sensitive marker of early lung function abnormalities in children with cystic fibrosis (9) and is increasingly being used a key outcome measure in cystic fibrosis therapy trials (1012). Reports on the diagnostic utility of $\mathrm{LCl}$ and other indices of ventilation inhomogeneity in preterm infants with and without BPD are controversial: Whereas some authors reported increased $\mathrm{LCl}$ in preterm vs. term infants and an association of $\mathrm{LCl}$ with the duration of oxygen supplementation $(13,17)$, more recent studies did not confirm these results $(15,16)$. The reason for the marked difference in diagnostic utility of $\mathrm{LCl}$ in cystic fibrosis vs. BPD infants is unclear and requires further investigation. Our finding of normal $\mathrm{LCl}$ values in infants with moderate to severe BPD is counterintuitive as BPD is thought to result in ventilation inhomogeneity due to abnormal acinar development. Given that histological features of current phenotypes of BPD suggest the primary zone of injury to be located in the lung periphery, heterogeneous ventilation and flow asynchrony on emptying of peripheral lung units is very likely. However, the magnitude and range of ventilation inhomogeneity occurring in current phenotypes of BPD are unknown and may be lower than those found in cystic fibrosis. Thus, sensitivity of $\mathrm{LCl}$ measured by $\mathrm{MBW}_{\mathrm{SF} 6}$ and an ultrasonic flow sensor might be too low to reveal peripheral ventilation inhomogeneity among infants with BPD (16). Further, due to differences in testing equipment and methods of analyses, comparing $\mathrm{LCl}$ values obtained from different laboratories and patient populations is difficult, although a recent consensus statement from leading researchers in the field will certainly help to standardize MBW testing in the future (28). Recent literature suggests that calculation of $\mathrm{LCl}$ derived from the EEMM versus EIMM signal might result in false normal $\mathrm{LCl}$ values (21). Our study confirms that $\mathrm{LCl}$ and aLCl values using the EIMM signal are higher than those derived from the EEMM signal. However, associations of $\mathrm{LCl}$ and aLCl with $V_{\mathrm{D}, \mathrm{MM}} / V_{\mathrm{T}}$ remained significant when using the EIMM signal. Further, recalculation of $\mathrm{LCl}$ and aLCl using the EIMM signal revealed no associations with neonatal lung disease including BPD, duration of supplemental oxygen, and duration of mechanical ventilation. High 
viscosity and low diffusivity of $\mathrm{SF}_{6}$ compared to other washout gases such as helium might result in relatively poor gas mixing efficiency of $\mathrm{MBW}_{\mathrm{SF}}$ even in the absence of true ventilation inhomogeneity (29). The single study suggesting a strong association between LCI and severity of BPD was done using nitrogen washout (14). High oxygen concentrations during nitrogen washout are known to induce atelectasis and influence breathing pattern in infants (30); therefore, it is difficult to determine to what degree $\mathrm{LCl}$ under these conditions reflects ventilation inhomogeneity due to underlying lung disease or, alternatively, is a result of artificial breathing pattern.

We expected that calculating aLCl compared to standard $\mathrm{LCl}$ would increase diagnostic utility of such indices in discriminating between preterm infants with and without BPD. Surprisingly, aLCl was not superior to $\mathrm{LCl}$ in distinguishing between health and disease in this population. Furthermore, regression analyses on aLCl did not result in meaningful associations with $V_{\mathrm{D}, \mathrm{MM}} / V_{\mathrm{T}}$ and produced several biologically questionable associations with demographic characteristics suggesting that calculating aLCl per se results in artificial overcorrection of $V_{\mathrm{D}}$. We are not aware of other studies comparing $\mathrm{aLCl}$ and $\mathrm{LCl}$ in preterm infants. Haidopoulou et al. compared aLCl and standard LCl in infants and children aged $0.1-$ 10.7 years for detection of early cystic fibrosis lung disease. They found that $\mathrm{LCl}$ is only minimally affected by $V_{D}$ and aLCl is not more sensitive than standard $\mathrm{LCl}$ in children with cystic fibrosis (31).

The strengths of our study include a large sample size of infants born within a wide range of GA and a broad spectrum of neonatal lung disease. Study participants were investigated at two sites using identical equipment and MBW protocols. Further, measurements were performed according to ERS/ATS guidelines $(19,20)$ during quiet, unsedated sleep reflecting physiological conditions. Additionally, $V_{\mathrm{D}, \mathrm{MM}} / V_{\mathrm{T}}$ derived from the molar mass signal was estimated individually for each patient rather than averaged by simply adding apparatus $V_{D}$ and assumed anatomical $V_{\mathrm{D}}$ per kg body weight. 
Limitations of our study include the retrospective design and use of a clinical rather than a physiological definition of BPD; we did not conduct a formal oxygen reduction test to classify severity of BPD (32), potentially introducing misclassification bias. However, such bias does not explain the lack of differences in LCl between healthy term infants, healthy preterm infants, and preterm infants with moderate to severe BPD. Further, we assessed the relationship between $\mathrm{LCl}$ and the total duration of oxygen supplementation during hospital stay and found that the latter does not predict $\mathrm{LCl}$, supporting the view that we did not miss a strong association of LCl with BPD due to misclassification bias. We studied infants at two sites. Infants studied in Perth were of slightly lower PMA (Perth, 39.6 w versus Berne, 44.7 w) and some lung function results $\left(\mathrm{aLCl}, V_{\mathrm{T}} / \mathrm{kg}\right.$, respiratory rate, $V_{\mathrm{D}, \mathrm{MM}} / V_{\mathrm{T}}, \mathrm{V}_{\mathrm{alv}} / \mathrm{kg}$; Table 2) differed between centres despite identical measurement protocols. Thus, we included centre variable into multivariable regression models in order to improve the predictive value of the models, however, the main associations between indices of ventilation inhomogeneity and $V_{\mathrm{D}, \mathrm{MM}} / V_{\mathrm{T}}$ did not change.

Considering the uncertain diagnostic utility of $\mathrm{LCl}$ and the ongoing lack of a reliable, continuous outcome measure in clinical BPD trials, other tests such as tidal breathing including volumetric capnography might be considered for evaluation of lung function impairment in these infants; volumetric capnography is applicable in unsedated, spontaneously breathing small infants and the phase III slope derived from volumetric capnograpy is steeper in infants with BPD independently from lung volume, breathing pattern and degree of prematurity, allowing for a quantitative assessment of impaired gas exchange (33). Volumetric capnography is relatively easy to perform in a clinical setting, does not require complex MBW equipment, is applicable in patients breathing room air and in those requiring supplemental oxygen, and most importantly, its indices quantitatively reflect the degree of neonatal lung disease in former preterm infants (33). Thus, these 
indices should be explored further both for monitoring of infants with neonatal lung disease and as future outcome measures for clinical trials in infants with BPD. 


\section{Conclusions}

We conclude that $V_{\mathrm{D}, \mathrm{MM}} / V_{\mathrm{T}}$ moderately influences $\mathrm{LCl}$ in preterm infants with and without BPD. Accounting for $V_{\mathrm{D}, \mathrm{MM}} / V_{\mathrm{T}}$ does not reveal a strong association of $\mathrm{LCl}$ with $\mathrm{BPD}$. Further research is required to develop tests that are useful to objectively quantify early lung function impairment in preterm infants. 


\section{Acknowledgments:}

Funding source: Women and Infants Research Foundation, Viertel Senior Medical Research Fellowship and Raine Medical Research Foundation (JJP). Swiss National Science Foundation (grant 3200-B0-112099) (UF). We are grateful to Ramona Lienhard and Barbara Egger for assistance in data analysis and Philipp Latzin for methodological advice. 
Fig. 1. Positive association of dead space to tidal volume ratio $\left(V_{\mathrm{D}, \mathrm{MM}} / V_{\mathrm{T}}\right)$ and lung clearance index $(\mathrm{LCl}) ; r^{2}=0.13, p<0.001$. 


\section{References}

1. Jobe AH, Bancalari E. Bronchopulmonary dysplasia. Am J Respir Crit Care Med. 2001;163(7):1723-1729.

2. Stoll BJ, Hansen NI, Bell EF, Shankaran S, Laptook AR, Walsh MC, et al. Neonatal outcomes of extremely preterm infants from the NICHD Neonatal Research Network. Pediatrics. 2010;126(3):443-456.

3. Coalson JJ. Pathology of bronchopulmonary dysplasia. Semin Perinatol. 2006;30(4):179-184.

4. Baraldi E, Filippone M. Chronic lung disease after premature birth. N Engl J Med. 2007;357(19):1946-1955.

5. Filippone M, Bonetto G, Cherubin E, Carraro S, Baraldi E. Childhood course of lung function in survivors of bronchopulmonary dysplasia. JAMA. 2009;302(13):1418-1420.

6. Fakhoury KF, Sellers C, Smith EO, Rama JA, Fan LL. Serial measurements of lung function in a cohort of young children with bronchopulmonary dysplasia. Pediatrics. 2010;125(6):e1441-1447.

7. Jobe AH. The new bronchopulmonary dysplasia. Curr Opin Pediatr. 2011;23(2):167172.

8. Fuchs SI, Gappa M. Lung clearance index: clinical and research applications in children. Paediatr Respir Rev. 2011;12(4):264-270.

9. Aurora P, Bush A, Gustafsson P, Oliver C, Wallis C, Price J, et al. Multiple-breath washout as a marker of lung disease in preschool children with cystic fibrosis. Am J Respir Crit Care Med. 2005;171(3):249-256.

10. Amin R, Subbarao P, Jabar A, Balkovec S, Jensen R, Kerrigan $S$, et al. Hypertonic saline improves the $\mathrm{LCl}$ in paediatric patients with $\mathrm{CF}$ with normal lung function. Thorax. 2010;65(5):379-383.

11. Amin R, Subbarao P, Lou W, Jabar A, Balkovec S, Jensen R, et al. The effect of dornase alfa on ventilation inhomogeneity in patients with cystic fibrosis. Eur Respir J. 2011;37(4):806-812.

12. Horsley AR, Davies JC, Gray RD, Macleod KA, Donovan J, Aziz ZA, et al. Changes in physiological, functional and structural markers of cystic fibrosis lung disease with treatment of a pulmonary exacerbation. Thorax. 2013;68(6):532-539.

13. Hjalmarson $\mathrm{O}$, Sandberg K. Abnormal lung function in healthy preterm infants. Am J Respir Crit Care Med. 2002;165(1):83-87.

14. Hjalmarson $\mathrm{O}$, Sandberg KL. Lung function at term reflects severity of bronchopulmonary dysplasia. J Pediatr. 2005;146(1):86-90.

15. Schulzke SM, Hall GL, Nathan EA, Simmer K, Nolan G, Pillow JJ. Lung volume and ventilation inhomogeneity in preterm infants at 15-18 months corrected age. J Pediatr. 2010;156(4):542-549 e542.

16. Latzin P, Roth S, Thamrin C, Hutten GJ, Pramana I, Kuehni CE, et al. Lung volume, breathing pattern and ventilation inhomogeneity in preterm and term infants. PLoS One. 2009;4(2):e4635.

17. Hulskamp G, Lum S, Stocks J, Wade A, Hoo AF, Costeloe K, et al. Association of prematurity, lung disease and body size with lung volume and ventilation inhomogeneity in unsedated neonates: a multicentre study. Thorax. 2009;64(3):240-245.

18. Verbanck S, Paiva M, Schuermans D, Hanon S, Vincken W, Van Muylem A. Relationships between the lung clearance index and conductive and acinar ventilation heterogeneity. J Appl Physiol. 2012;112(5):782-790.

19. Bates JH, Schmalisch G, Filbrun D, Stocks J. Tidal breath analysis for infant pulmonary function testing. ERS/ATS Task Force on Standards for Infant Respiratory Function Testing. 
European Respiratory Society/American Thoracic Society. Eur Respir J. 2000;16(6):11801192.

20. Frey U, Stocks J, Coates A, Sly P, Bates J. Specifications for equipment used for infant pulmonary function testing. ERS/ATS Task Force on Standards for Infant Respiratory Function Testing. European Respiratory Society/ American Thoracic Society. Eur Respir J. 2000;16(4):731-740.

21. Anagnostopoulou P, Yammine S, Schmidt A, Korten I, Kieninger E, Mack I, et al. False normal Lung Clearance Index in infants with cystic fibrosis due to software algorithms. Pediatr Pulmonol. 2015;50(10):970-977.

22. Thamrin C, Latzin P, Sauteur L, Riedel T, Hall GL, Frey U. Deadspace estimation from CO2 versus molar mass measurements in infants. Pediatr Pulmonol. 2007;42(10):920-927.

23. Freeman JV, Cole TJ, Chinn S, Jones PR, White EM, Preece MA. Cross sectional stature and weight reference curves for the UK, 1990. Arch Dis Child. 1995;73(1):17-24.

24. Schmalisch G, Proquitte H, Roehr CC, Wauer RR. The effect of changing ventilator settings on indices of ventilation inhomogeneity in small ventilated lungs. BMC Pulm Med. 2006;6:20.

25. Schmalisch G, Wilitzki S, Buhrer C, Fischer HS. The lung clearance index in young infants: impact of tidal volume and dead space. Physiol Meas. 2015;36(7):1601-1613.

26. Cote CJ, Karl HW, Notterman DA, Weinberg JA, McCloskey C. Adverse sedation events in pediatrics: analysis of medications used for sedation. Pediatrics. 2000;106(4):633644.

27. Kosch PC, Stark AR. Dynamic maintenance of end-expiratory lung volume in full-term infants. J Appl Physiol Respir Environ Exerc Physiol. 1984;57(4):1126-1133.

28. Robinson PD, Latzin P, Verbanck S, Hall GL, Horsley A, Gappa M, et al. Consensus statement for inert gas washout measurement using multiple- and single- breath tests. Eur Respir J. 2013;41(3):507-522.

29. Harris EA, Buchanan PR, Whitlock RM. Human alveolar gas-mixing efficiency for gases of differing diffusivity in health and airflow limitation. Clin Sci (Lond). 1987;73(4):351359.

30. Burger EJ, Jr., Macklem P. Airway closure: demonstration by breathing 100 percent O2 at low lung volumes and by N2 washout. J Appl Physiol. 1968;25(2):139-148.

31. Haidopoulou K, Lum S, Turcu S, Guinard C, Aurora P, Stocks J, et al. Alveolar LCI vs. standard LCl in detecting early CF lung disease. Respir Physiol Neurobiol. 2012;180(2-3):247251.

32. Walsh $M C$, Yao $Q$, Gettner $P$, Hale E, Collins $M$, Hensman A, et al. Impact of a physiologic definition on bronchopulmonary dysplasia rates. Pediatrics. 2004;114(5):13051311.

33. Fouzas S, Hacki C, Latzin P, Proietti E, Schulzke S, Frey U, et al. Volumetric capnography in infants with bronchopulmonary dysplasia. J Pediatr. 2014;164(2):283-288 e281-283. 
Table 1

Baseline Characteristics of Study Infants

Healthy

Bronchopulmonary dysplasia*

\begin{tabular}{|c|c|c|c|c|}
\hline & Term & $\begin{array}{l}\text { Preterm (no } \\
\text { BPD) }\end{array}$ & Mild & $\begin{array}{l}\text { Moderate to } \\
\text { severe }\end{array}$ \\
\hline Total, $n$ & 222 & 102 & 44 & 87 \\
\hline Total No Berne & 187 & 43 & 35 & 70 \\
\hline Total No Perth & 35 & 59 & 9 & 17 \\
\hline Gender male, $\mathrm{n}(\%)$ & $123(55.4)$ & $50(49.0)$ & $31(70.5)$ & $55(63.2)$ \\
\hline Gestational age, weeks & $\begin{array}{l}39.8 \\
( \pm 1.2)\end{array}$ & $31.6( \pm 2.4)$ & $27.8( \pm 2.7)$ & $27.6( \pm 2.2)$ \\
\hline PMA at test, weeks & $\begin{array}{l}44.8 \\
( \pm 1.3)\end{array}$ & $40.0( \pm 4.5)$ & $43.1( \pm 3.2)$ & $43.7( \pm 3.3)$ \\
\hline Birth weight, kg & $3.4( \pm 0.4)$ & $1.6( \pm 0.5)$ & $1.1( \pm 0.4)$ & $0.9( \pm 0.4)$ \\
\hline Birth weight z-score & $-0.1( \pm 0.9)$ & $-0.7( \pm 1.2)$ & $-0.5( \pm 1.1)$ & $-0.8( \pm 1.2)$ \\
\hline Weight at test, kg & $4.4( \pm 0.6)$ & $3.0( \pm 1.1)$ & $3.7( \pm 0.9)$ & $3.6( \pm 0.9)$ \\
\hline Weight z-Score & $-0.1( \pm 0.9)$ & $-0.7( \pm 1.2)$ & $-0.9( \pm 1.2)$ & $-1.3( \pm 1.2)$ \\
\hline Length at test, $\mathrm{cm}$ & $\begin{array}{l}55.2 \\
( \pm 2.2)\end{array}$ & $48.3( \pm 4.9)$ & $50.7( \pm 3.8)$ & $49.9( \pm 4.2)$ \\
\hline $\mathrm{BMI}$ at test, $\mathrm{kg} / \mathrm{m}^{2}$ & $\begin{array}{l}14.5 \\
( \pm 1.4)\end{array}$ & $12.4( \pm 2.2)$ & $14.0( \pm 2.0)$ & $14.2( \pm 1.9)$ \\
\hline Supplemental $\mathrm{O}_{2}$, days & 0 & $4.8( \pm 7.1)$ & $49.7( \pm 17.5)$ & $81.7( \pm 28.1)$ \\
\hline Mechanical ventilation, days & 0 & $0.3( \pm 0.5)$ & $8.2( \pm 13)$ & $10.5( \pm 16.2)$ \\
\hline $\begin{array}{l}\text { Respiratory distress } \\
\text { syndrome, n (\%) }\end{array}$ & 0 & $60(59)$ & $44(100)$ & $87(100)$ \\
\hline Passive smoke exposure, n (\%) & $27(12.2)$ & $11(10.8)$ & 7 (15.9) & $13(26.4)$ \\
\hline
\end{tabular}


*BPD categorized as mild $\left(\mathrm{O}_{2}\right.$ for $\geq 28$ days and in room air at 36 weeks PMA) and moderate to severe $\left(\mathrm{O}_{2}\right.$ for $\geq 28$ days and $\mathrm{O}_{2}$ requirement $>21 \%$ or CPAP at 36 weeks PMA). Data is presented as mean $( \pm S D)$ if not stated otherwise. PMA, post-menstrual age; $B M I$, body mass index. The following variables were significantly lower in Perth compared to Bern (t-test; $p$ value < 0.05): gestational age, PMA at test, birth weight, weight, weight z-score, length, BMI. 
Table 2

Results of Lung Function Tests

\begin{tabular}{|c|c|c|c|c|c|}
\hline & \multicolumn{2}{|l|}{ Healthy } & \multicolumn{2}{|c|}{ Bronchopulmonary dysplasia } & \multirow[t]{2}{*}{$p$ value } \\
\hline & Term & Preterm & Mild & Moderate to severe & \\
\hline \multirow[t]{2}{*}{$\mathrm{FRC} / \mathrm{kg}(\mathrm{mL} / \mathrm{kg})$} & $23.9(4.8)$ & 25.3 & 24.5 & $23.9(5.0)^{*}$ & $<0.01$ \\
\hline & & $(5.5)^{+}$ & $(4.6)$ & & \\
\hline \multirow[t]{2}{*}{$\mathrm{FRC}(\mathrm{mL})^{\circ}$} & 104.2 & 78.8 & 88.7 & $84.6(23.5)^{+}$ & $<0.01$ \\
\hline & $(18.6)$ & $(26.4)^{+}$ & $(22.7)^{+}$ & & \\
\hline $\mathrm{LCl}$ & $7.0(0.7)$ & $6.9(0.7)$ & $6.9(0.7)$ & $7.0(0.8)$ & 0.659 \\
\hline $\mathrm{aLCl}^{\circ}$ & $5.6(0.5)$ & $5.7(0.8)$ & $5.4(0.7)$ & $5.4(0.6)^{*}$ & $<0.01$ \\
\hline$V_{\mathrm{T}} / \mathrm{kg}(\mathrm{mL} / \mathrm{kg})^{\circ}$ & $7.0(1.2)$ & $7.1(1.4)$ & $6.8(1.2)$ & $6.4(1.3)^{+*}$ & $<0.01$ \\
\hline Respiratory rate & $45.4(11.0)$ & 53.7 & 51.6 & $55.1(15.1)^{+}$ & $<0.01$ \\
\hline 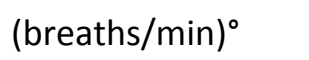 & & $(13.2)^{+}$ & $(9.4)^{+}$ & & \\
\hline Minute ventilation & 319.8 & 377.7 & 354.2 & $366.2(94.4)^{+}$ & $<0.01$ \\
\hline$(\mathrm{mL} / \mathrm{kg})$ & $(57.1)$ & $(83.1)^{+}$ & $(65.9)^{+}$ & & \\
\hline \multirow[t]{2}{*}{$V_{\mathrm{D}, \mathrm{MM}} / \mathrm{kg}(\mathrm{mL} / \mathrm{kg})$} & $1.8(0.3)$ & 2.0 & 1.8 & $1.8(0.5)^{*}$ & $<0.01$ \\
\hline & & $(0.5)^{+}$ & $(0.5)^{*}$ & & \\
\hline \multirow[t]{2}{*}{$V_{\mathrm{D}, \mathrm{MM}} / V_{\mathrm{T}}^{\circ}$} & $0.26(0.05)$ & 0.29 & 0.27 & $0.29(0.07)^{+}$ & $<0.01$ \\
\hline & & $(0.06)^{+}$ & $(0.06)$ & & \\
\hline$V_{\text {alv }} / \mathrm{kg}(\mathrm{mL} / \mathrm{kg})^{\circ}$ & $5.2(1.0)$ & $5.0(1.3)$ & $4.9(1.0)$ & $4.6(1.2)^{+*}$ & $<0.01$ \\
\hline \multicolumn{6}{|c|}{ Data is presented as mean $( \pm S D)$. $F R C$, functional residual capacity; $\mathrm{LCl}$, lung clearance index; } \\
\hline \multicolumn{6}{|c|}{ aLCl, alveolar lung clearance index; $V_{\mathrm{T}}$, tidal volume; $V_{\mathrm{D}, \mathrm{MM}}$, respiratory dead space; $V_{\mathrm{D}, \mathrm{MM}} V_{\mathrm{T}}$, } \\
\hline \multicolumn{6}{|c|}{ dead space to tidal volume ratio; $V_{\text {alv }}$, alveolar tidal volume. ${ }^{+} p<0.05$ vs. Term; ${ }^{*} p<0.05$ vs. } \\
\hline
\end{tabular}


Table 3

Results of Univariable Regression Analysis of LCI

\begin{tabular}{|c|c|c|c|}
\hline Explanatory variable & Coef $\beta$ & $95 \% \mathrm{Cl}^{\mathrm{b}}$ & $p$ value \\
\hline Centre & 0.041 & $-0.102,0.184$ & 0.57 \\
\hline \multicolumn{4}{|l|}{$\mathrm{BPD}^{\mathrm{c}}$} \\
\hline Preterm, no BPD & -0.003 & $-0.164,0.158$ & 0.97 \\
\hline Preterm, mild BPD & -0.056 & $-0.278,0.166$ & 0.62 \\
\hline Preterm, moderate/severe BPD & 0.087 & $-0.083,0.258$ & 0.31 \\
\hline Term & -0.018 & $-0.144,0.108$ & 0.78 \\
\hline Gestational age & -0.001 & $-0.012,0.010$ & 0.91 \\
\hline Postmenstrual age & -0.038 & $-0.014,0.022$ & 0.68 \\
\hline Postmenstrual age $>40 \mathrm{w}$ & 0.124 & $-0.044,0.293$ & 0.15 \\
\hline Birth weight z-score & -0.021 & $-0.077,0.036$ & 0.47 \\
\hline Weight at test & -0.005 & $-0.069,0.058$ & 0.87 \\
\hline Weight z-score at test & -0.033 & $-0.087,0.022$ & 0.24 \\
\hline Length at test & -0.003 & $-0.017,0.011$ & 0.67 \\
\hline Days of supplemental oxygen ${ }^{d}$ & 0.002 & $-0.0002,0.003$ & 0.09 \\
\hline Duration of mechanical ventilation & 0.0001 & $-0.0002,0.0004$ & 0.37 \\
\hline$V_{\mathrm{D}, \mathrm{MM}} / V_{\mathrm{T}}$ & 4.207 & $3.202,5.211$ & $<0.001$ \\
\hline $\mathrm{MV} / \mathrm{kg}$ & 0.001 & $0.0004,0.002$ & 0.003 \\
\hline Sex & 0.0002 & $-0.127,0.127$ & 0.99 \\
\hline Passive smoke exposure & 0.140 & $-0.051,0.332$ & 0.15 \\
\hline
\end{tabular}

${ }^{a}$ Regression coefficient $\beta ;{ }^{b} 95 \%$ confidence interval; ${ }^{c}$ Reference level: term infants; ${ }^{d}$ Days of supplemental oxygen until lung function test; $\mathrm{LCl}$, lung clearance index; $\mathrm{BPD}$, bronchopulmonary dysplasia; $V_{\mathrm{T}}$, tidal volume; $V_{\mathrm{D}, \mathrm{MM}} V_{\mathrm{T}}$, dead space to tidal volume ratio; $\mathrm{MV} / \mathrm{kg}$, minute volume per $\mathrm{kg}$ body weight. 
Table 4

Results of Multivariable Regression Analysis of $\mathrm{LCI}$

\begin{tabular}{llll}
\hline Explanatory variable & Coef $\boldsymbol{\beta}^{\mathrm{a}}$ & $\mathbf{9 5 \%} \mathrm{Cl}^{\mathrm{b}}$ & $\boldsymbol{p}$ value \\
\hline Model 2 $\left(\boldsymbol{r}^{\mathrm{cc}}=\mathbf{0 . 1 9 ;} \boldsymbol{p}<\mathbf{0 . 0 0 1}\right.$; intercept 4.63) & & & \\
\hline$V_{\mathrm{D}, \mathrm{MN}} V_{\mathrm{T}}$ & 5.234 & $4.192,6.276$ & $<0.001$ \\
Centre & 0.275 & $0.092,0.458$ & 0.003 \\
Postmenstrual age $>40 \mathrm{w}$ & 0.650 & $0.424,0.876$ & $<0.001$ \\
\hline
\end{tabular}

$\mathrm{LCl}$, lung clearance index; ${ }^{a}$ regression coefficient $\beta ;{ }^{b} 95 \%$ confidence interval; ${ }^{c}$ coefficient of determination; $V_{\mathrm{D}, \mathrm{MM}} V_{\mathrm{T}}$, dead space to tidal volume ratio. 
Table 5

Results of Univariable Regression Analysis of Alveolar LCI

\begin{tabular}{|c|c|c|c|}
\hline Explanatory variable & Coef $\beta^{a}$ & $95 \% \mathrm{Cl}^{\mathrm{b}}$ & $p$ value \\
\hline Centre & -0.176 & $-0.312,-0.040$ & 0.001 \\
\hline \multicolumn{4}{|l|}{$\mathrm{BPD}^{\mathrm{c}}$} \\
\hline Preterm, no BPD & -0.553 & $-0.723,-0.380$ & $<0.001$ \\
\hline Preterm, mild BPD & -0.167 & $-0.406,0.073$ & 0.172 \\
\hline Preterm, moderate/severe BPD & -0.210 & $-0.393,-0.027$ & 0.025 \\
\hline Term & 0.349 & $0.211,0.487$ & $<0.001$ \\
\hline Gestational age & 0.023 & $0.015,0.0 .039$ & $<0.001$ \\
\hline Postmenstrual age & 0.113 & $0.096,0.131$ & $<0.001$ \\
\hline Postmenstrual age $>40 \mathrm{w}$ & 1.133 & $0.975,1.291$ & $<0.001$ \\
\hline Birth weight z-score & 0.053 & $-0.011,0.116$ & 0.102 \\
\hline Weight at test & 0.384 & $0.322,0.447$ & $<0.001$ \\
\hline Weight z-score at test & 0.144 & $0.084,0.205$ & $<0.001$ \\
\hline Length at test & 0.082 & $0.069,0.095$ & $<0.001$ \\
\hline Days of supplemental oxygen ${ }^{d}$ & -0.001 & $-0.002,0.002$ & 0.951 \\
\hline Duration of mechanical ventilation & -0.0003 & $-0.0001,0.0001$ & 0.125 \\
\hline$V_{\mathrm{D}, \mathrm{MM}} V_{\mathrm{T}}$ & -5.080 & $-6.193,-3.697$ & $<0.001$ \\
\hline $\mathrm{MV} / \mathrm{kg}$ & -0.001 & $-0.002,-0.0001$ & 0.019 \\
\hline Sex & 0.132 & $0.013,0.251$ & 0.029 \\
\hline Passive smoke exposure & -0.015 & $-0.194,0.164$ & 0.871 \\
\hline
\end{tabular}

${ }^{\mathrm{a}}$ Regression coefficient $\beta$; ${ }^{\mathrm{b}} 95 \%$ confidence interval; ${ }^{\mathrm{c}}$ Reference level: term infants; ${ }^{\mathrm{d}}$ Days of supplemental oxygen until lung function test; $\mathrm{LCl}$, lung clearance index; $\mathrm{BPD}$, bronchopulmonary dysplasia; $V_{\mathrm{T}}$, tidal volume; $V_{\mathrm{D}, \mathrm{Mm}} V_{\mathrm{T}}$, dead space to tidal volume ratio; $\mathrm{MV} / \mathrm{kg}$, minute volume per kg body weight. 
Table 6

Results of Multivariable Regression Analysis of Alveolar LCI

\begin{tabular}{llll}
\hline Explanatory variable & Coef $\boldsymbol{\beta}^{\mathrm{a}}$ & $\mathbf{9 5 \%} \mathrm{Cl}^{\mathrm{b}}$ & $\boldsymbol{p}$ value \\
\hline Final model $\left(\boldsymbol{r}^{2 \mathrm{c}}=\mathbf{0 . 4 7} \boldsymbol{p}<\mathbf{0 . 0 0 1}\right.$; intercept 4.57) & & \\
\hline$V_{\mathrm{D}, \mathrm{MM}} V_{\mathrm{T}}$ & -2.420 & $-3.340,-1.500$ & $<0.001$ \\
Centre & -0.436 & $-0.587,-0.285$ & $<0.001$ \\
Postmenstrual age $>40 \mathrm{w}$ & 0.439 & $0.218,0.660$ & $<0.001$ \\
Length & 0.025 & $0.009,0.041$ & 0.002 \\
\hline
\end{tabular}

$\mathrm{LCl}$, lung clearance index; ${ }^{a}$ regression coefficient $\beta ;{ }^{b} 95 \%$ confidence interval; ${ }^{c}$ coefficient of determination; $V_{\mathrm{D}, \mathrm{MM}} V_{\mathrm{T}}$, dead space to tidal volume ratio. 


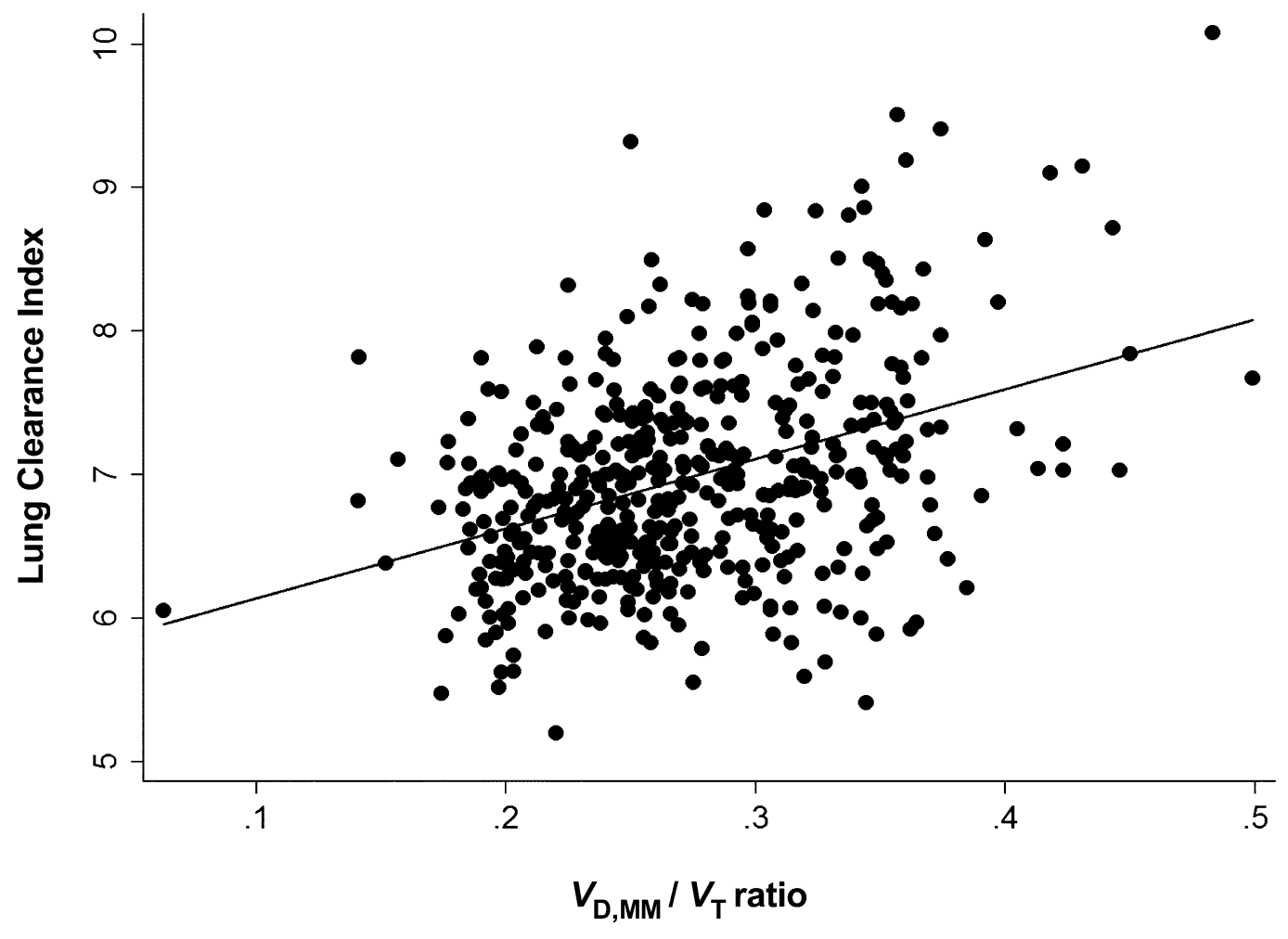

